\title{
Detection of Staphylococcus aureus with biotinylated monoclonal antibodies directed against staphylococcal TNase complexed to avidin-peroxidase in a rapid sandwich enzyme-linked immunofiltration assay (sELIFA)
}

\author{
O. G. BRAKSTAD*† and J. A. MAELAND $\dagger$ \\ * Applied Chemistry Division, SINTEF, N-7034 Trondheim and †Faculty of Medicine, University of Trondheim, \\ N-7006 Trondheim, Norway
}

\begin{abstract}
Summary. For rapid identification of Staphylococcus aureus, a monoclonal antibody (MAb)biotin-avidin-peroxidase complex, directed against the $S$. aureus thermostable nuclease (TNase), was formed and used in a rapid three-step sandwich enzyme-linked immunofiltration assay (sELIFA) and a three-step sandwich enzyme-linked immunosorbent assay (sELISA). The MAb-peroxidase complex was formed by incubating the biotinylated MAbs with a streptavidin-peroxidase conjugate and the complex was purified by gel permeation chromatography. When compared with a four-step MAb-based sELISA described previously, this complex permitted one reagent step to be omitted in a three-step sELISA, and the test time was significantly reduced. The test sensitivity was slightly reduced in the three-step ELISA (detection limit 1.0-2.0 ng of TNase/ml) when compared to the four-step sELISA (detection limit $0.5-1.0 \mathrm{ng}$ of TNase $/ \mathrm{ml}$ ). The SELIFA method was based on the filtration of bacterial culture supernates through nitrocellulose membrane disks pre-spotted with a MAb directed against the $S$. aureus TNase, followed by detection with the MAb-peroxidase complex (threestep sELIFA). A detection limit of $0 \cdot 5-2 \cdot 0 \mathrm{ng}$ of TNase $/ \mathrm{ml}$ was achieved with the three-step sELIFA, depending on the filtrate volume of culture supernates. The total test time was 10-15 min when pre-spotted and blocked membranes were used. A total of 85 bacterial strains was tested in the sELIFA. All the 28 S. aureus strains showed positive results, but none of the 57 non-S. aureus strains did so, although some of these produced thermostable nuclease activity. When 75 blood cultures were tested directly in the sELIFA, $87 \%$ of the cultures with growth of $S$. aureus gave a positive result whereas all of the cultures with non-S. aureus gave negative results, a diagnostic sensitivity similar to that of the routine TNase enzyme test. Thus, the three-step sELIFA has potential for the rapid confirmation of $S$. aureus bacteraemia and, possibly, also for detecting $S$. aureus by direct testing of other clinical specimens.
\end{abstract}

\section{Introduction}

Infections caused by Staphylococcus aureus are usually diagnosed by cultural isolation of the bacteria which are then identified by the coagulase test or by one of several commercial reagents based on particle agglutination of $S$. aureus. These reagents for rapid identification usually have a high sensitivity and specificity for $S$. aureus cultured on artificial media, but not for direct identification of staphylococci in media used for blood cultures. ${ }^{1}$ Blood cultures in which $S$. aureus has grown usually give a positive test result for thermostable nuclease (TNase) within $2-4 \mathrm{~h}$ after initiation of the test. ${ }^{2-4}$ However, this enzyme activity is not specific to $S$. aureus. ${ }^{5,6}$ On the other hand, the TNase protein which probably is produced

Received 3 Sept. 1992; accepted 4 Jan. 1993. by all $S$. aureus strains, ${ }^{4}$ and the $n u c$ gene encoding the enzyme,,$^{7,8}$ have $S$. aureus-specific sequences. Thus, monoclonal antibodies (MAbs) directed against three different $S$. aureus TNase epitopes showed specificity for bacteria of this species. ${ }^{9}$ In a MAb-based sandwich ELISA (sELISA), the lower detection limit for the TNase was $0.5 \mathrm{ng} / \mathrm{ml} .{ }^{9}$ The TNase sELISA has interesting potential for same-day confirmation of $S$. aureus bacteraemia and possibly for direct application to other clinical specimens.

The conventional multilayer sELISA is time-consuming with an operation time of $c .4 \mathrm{~h}$. In this study we aimed to reduce the assay time in the MAb-based detection of $S$. aureus TNase. Taking advantage of the high affinity of biotin for avidin, ${ }^{10}$ we prepared a fourcomponent complex that contained biotinylated antiTNase MAbs and a streptavidin-peroxidase conjugate to shorten the time required for the TNase sELISA 
test. In addition, the four-component complex was used in a sandwich enzyme-linked immunofiltration assay (sELIFA) to reduce the time required for immunological detection of the $S$. aureus TNase. In the sELIFA, previously used in the diagnosis of several infectious diseases, ${ }^{11}$ the rate of contact between the reagents is considerably increased, allowing a corresponding reduction in incubation period for each immunoreagent.

\section{Materials and methods}

\section{Bacterial strains}

The $S$. aureus strains Wood 46 and Cowan 1 were from Dr P. Oeding, Bergen, Norway. Several strains of $S$. hyicus, $S$. intermedius and S. schleiferi were supplied by Dr T. Wadström, Lund, Sweden. Reference strains were purchased from ATCC (American Type Culture Collection, Rockville, MA, USA) and DSM (Deutsche Sammlung von Mikroorganismen und Zellkulturen, Braunschweig, Germany). Clinical strains were isolated in our laboratory. Staphylococci were identified biochemically by the automated API Staph System (API Systems SA, Montralieu, Vercieu, France), and by the Staphylase test (Oxoid). Nonstaphylococcal clinical strains were identified by the appropriate API systems. Strains were preserved in Stuart's transport medium at $-80^{\circ} \mathrm{C}$.

\section{Culture}

Bacteria were cultured on blood agar or in Brain Heart Infusion Broth (BHI; Difco) at $37^{\circ} \mathrm{C}$ for 16-20 h. The fluid cultures were centrifuged $(12000 \mathrm{~g}$, $10 \mathrm{~min})$ and the supernate was heated $\left(100^{\circ} \mathrm{C}, 15 \mathrm{~min}\right)$ and tested. For blood culture, the Bactec 730 system (Johnston Laboratories Inc., Towson, MD, USA) or Bactec Plus media were used. From cultures in which growth was signalled, samples were aspirated aseptically, heated at $100^{\circ} \mathrm{C}$ for $15 \mathrm{~min}$, and centrifuged $(12000 \mathrm{~g}, 10 \mathrm{~min})$. The supernate was filtered $(0 \cdot 2-\mu \mathrm{m}$ sterile membrane filter) before testing.

\section{TNase enzyme test}

The TNase enzyme test was performed as described by Berg and Maeland. ${ }^{2}$ Briefly, TNase or culture supernates were heated at $100^{\circ} \mathrm{C}$ for $15 \mathrm{~min}$, and $50 \mu \mathrm{l}$ was applied to wells in agar plates containing DNA and $o$-toluidine blue. The plates were incubated at room temperature and observed for a pink zone around the wells after incubation for 2, 4, 6 and $24 \mathrm{~h}$; the diameters of the zones were recorded.

\section{$M A b s$}

The anti-S. aureus TNase MAbs $2 \mathrm{~F} 11,7 \mathrm{~F} 11$ and 6G6 (all of the isotype IgG1) used in this study were described previously. ${ }^{9}$ Each MAb was directed against distinct TNase epitope clusters. MAb IgG was isolated from ascitic fluid, ${ }^{12}$ biotinylated ${ }^{13}$ with CAB-NHS ester (Gibco-BRL, Gaithersburgh, MD, USA), and stored at protein concentrations of $1 \mathrm{mg} / \mathrm{ml}$ in phosphate-buffered saline (PBS), $\mathrm{pH} 7 \cdot 2$, at $-20^{\circ} \mathrm{C}$.

\section{Preparation of $M A$ A-peroxidase complex}

Equal volumes of biotinylated MAbs 2 F11 and 6G6 (equilibrated in PBS by dialysis) were mixed and serially diluted in PBS. These dilutions were incubated in a chequerboard fashion at $4^{\circ} \mathrm{C}$ and $20^{\circ} \mathrm{C}$ with streptavidin-peroxidase conjugate (Gibco-BRL) equilibrated in PBS and serially diluted in PBS. Optimal conditions for complex formation were determined by testing against TNase in a sELISA (see Results). The MAb-peroxidase complex was purified on a Sephacryl S 300 column (Pharmacia LKB Biotechnology AB, Uppsala, Sweden; $3.0 \times 43 \mathrm{~cm}$ ). Biotinylated MAbs $(400 \mu \mathrm{l}$, protein $1 \mathrm{mg} / \mathrm{ml})$ were coupled to undiluted streptavidin-peroxidase $(800 \mu \mathrm{l})$, dialysed against PBS and chromatographed with PBS as elution buffer at a flow rate of $4 \mathrm{ml} / \mathrm{h} ; 2-\mathrm{ml}$ fractions were collected.

Samples from each fraction were diluted 1 in 100 in PBS with Tween $200.05 \% \mathrm{v} / \mathrm{v}$ (PBS-T) and tested in the three-step sELISA (see below) for recording MAbperoxidase complexes. For the estimation of free biotinylated MAbs in the fractions, samples diluted 1 in 100 in PBS-T were tested in the conventional fourstep sELISA (see below). Free biotinylated MAbs were calculated by subtracting the absorbance recorded in the three-step ELISA from that recorded in the four-step ELISA.

MAb-peroxidase peak fractions were pooled $(6 \mathrm{ml})$, dialysed against PBS with merthiolate $0.01 \%$, and stored at $4^{\circ} \mathrm{C}$.

\section{Sandwich ELISA (sELISA)}

The multilayer sELISA (four-steps with pre-coated plates) was performed essentially as described previously. ${ }^{9}$ Briefly, microtitration plates (Nunc, Roskilde, Denmark) were coated with the anti-TNase MAb 7F11 $(100 \mu \mathrm{l} ; 5 \mu \mathrm{g} / \mathrm{ml}$ in $0.1 \mathrm{M}$ carbonate buffer, pH $\left.9.6 ; 20^{\circ} \mathrm{C} ; 18 \mathrm{~h}\right)$. The wells were washed with PBS$\mathrm{T}$, blocked (casein hydrolysate $1 \mathrm{mg} / \mathrm{ml}$ in PBS-T) and then incubated successively $\left(1 \mathrm{~h}, 20^{\circ} \mathrm{C}\right)$ with the antigen-containing sample, the mixture of the biotinylated MAbs 2F11 and 6G6 (each $1 \mu \mathrm{g} / \mathrm{ml}$ ), the streptavidin-peroxidase conjugate ( 1 in 1000), each with washing between the incubation steps. Bound peroxidase was detected with $\mathrm{OPD}-\mathrm{H}_{2} \mathrm{O}_{2}$ (Organon Teknika BV, Boxtal, The Netherlands) in $0 \cdot 1 \mathrm{M}$ citratephosphate buffer $\left(20^{\circ} \mathrm{C}, 2 \mathrm{~min}\right)$. The substrate conversion was stopped with $2 \mathrm{M} \mathrm{H}_{2} \mathrm{SO}_{4}$ and the colour development was measured at $492 \mathrm{~nm}$.

In the three-step multilayer test, purified MAbperoxidase complex was diluted 1 in 50 in PBS-T and applied after incubation with the antigen-con- 


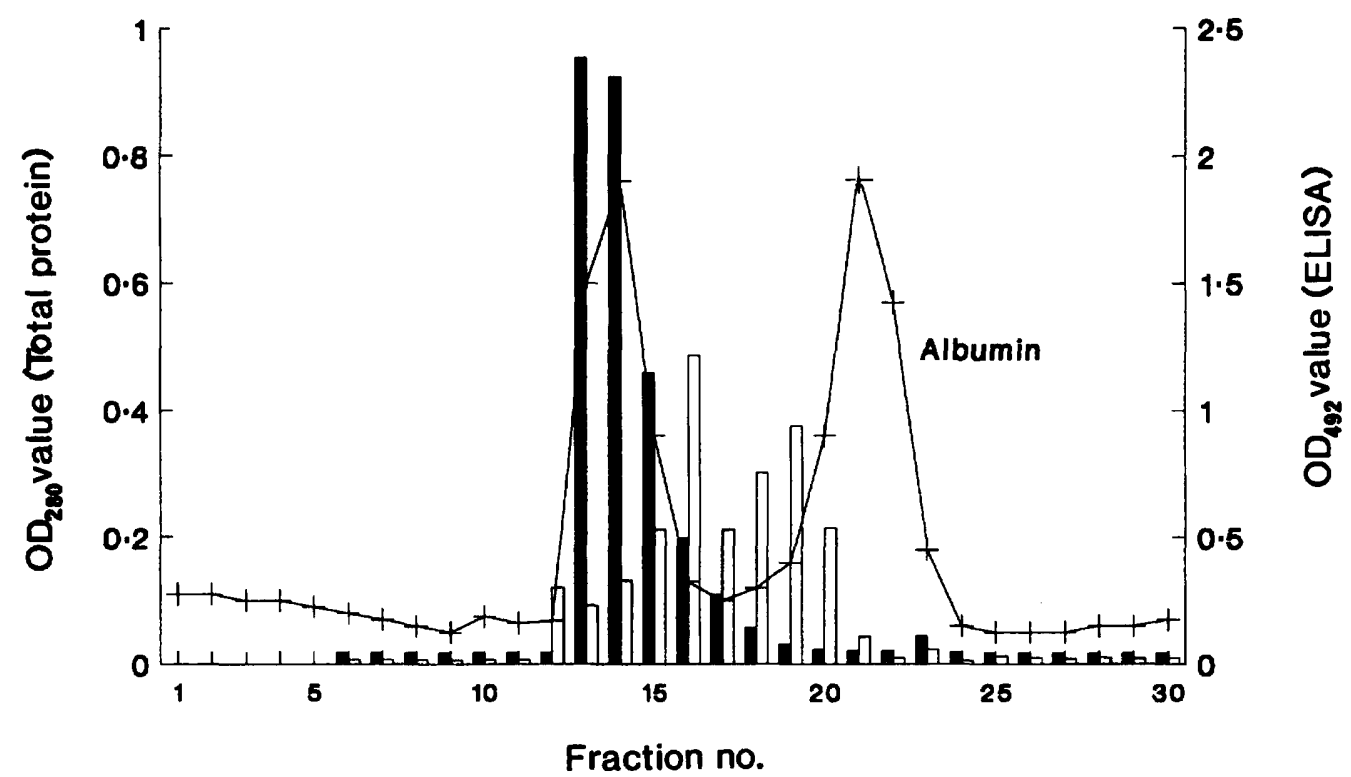

Fig. 1. Purification of a MAb-peroxidase complex by Sepharose S 300 gel permeation chromatography. Bovine serum albumin (1 mg/ml) was added as marker protein. The protein profile for the eluted fractions is shown by the curve $(+)$; the sELISA values for the MAb-peroxidase complex ( $\square$ ) and free biotinylated MÁbs ( $\square$ ) are shown by the bars.

taining sample, followed by washing and the substrate reaction.

\section{Sandwich enzyme-linked immunofiltration assay ( $s E L I F A)$}

An Octavac eight-place vacuum manifold filtration unit (Costar, Cambridge, MA, USA) was used with water suction and a filtration flow rate of $3 \mathrm{ml} / \mathrm{min}$. Circular nitrocellulose membrane disks (Costar; $0.45 \mu \mathrm{m}$ pore size, diameter $7 \mathrm{~mm}$ ) were dotted with $3 \mu \mathrm{l}$ of the MAb 7F11 (200 $\mu \mathrm{g} / \mathrm{ml}$ in PBS) and airdried. Remaining binding sites were blocked for $30 \mathrm{~min}$ with defatted dried milk $(10 \mathrm{mg} / \mathrm{ml}$ in PBS-T) and the membranes were washed by filtering $1.5 \mathrm{ml}$ of PBS-T. Antigen-containing solutions, biotinylated MAbs, streptavidin-peroxidase conjugates, or the complexes of these components, were filtered in a volume of $0.4 \mathrm{ml}$ and washed with $1.5 \mathrm{ml}$ of PBS-T between each reaction step. Colour development was accomplished with DAB $-\mathrm{H}_{2} \mathrm{O}_{2}$ (Sigma) $100 \mu \mathrm{l} /$ disk for 3-5 min and washing the disks in water. The results were recorded by visually observing for immunostained spots, corresponding to the grabber MAb dot (1-2 $\mathrm{mm}$ in diameter).

\section{Other methods}

Protein concentrations were measured by the method of Bradford..$^{14}$

\section{Results}

\section{Preparation of $M A b$-peroxidase complex}

Serial dilutions of a mixture of the biotinylated anti-
TNase MAbs 2F11 and 6G6 were mixed with serial dilutions of the peroxidase-streptavidin conjugate in a chequerboard fashion and incubated at $4^{\circ}$ and $20^{\circ} \mathrm{C}$ for various periods. The mixtures were tested in a three-step sELISA with MAb 7F11 coated to the wells and TNase as antigen, to measure MAb-mediated binding of the peroxidase. Optimal signals were achieved when the $\mathrm{MAb}$ and peroxidase were present in a ratio of $1: 2(1 \mathrm{ml}$ of biotinylated MAbs at $1 \mathrm{mg} / \mathrm{ml}$ mixed with $2 \mathrm{ml}$ of undiluted streptavidin-peroxidase) and both were equilibrated in PBS and then allowed to react at $4^{\circ} \mathrm{C}$ for $30 \mathrm{~min}$, then at $20^{\circ} \mathrm{C}$ for $60 \mathrm{~min}$. Incubation at $4^{\circ} \mathrm{C}$, followed by $20^{\circ} \mathrm{C}$, was chosen as a standard procedure. The macromolecular complex, which contained the biotinylated MAbs bound to the streptavidin-peroxidase conjugate, was purified by gel permeation chromatography on a Sephacryl S 300 column (fig. 1). Fractions 13-15, which contained the complex, were mixed, dialysed against PBS and used for further experiments at a dilution of 1 in 50 ( 1 in 300 when compared to the volume before purification). Free biotinylated MAbs were eluted in fractions 16-20 (fig. 1); free streptavidin-conjugated peroxidase was not detected.

Fig. 2 shows the signals obtained for the conventional four-step sELISA and the complex-based three-step sELISA with the purified complex. The four-step procedure resulted in stronger signals, notably with TNase concentrations $>4 \mathrm{ng} / \mathrm{ml}$. In repeated experiments, the lower limit of detection for TNase was $0.5-1.0 \mathrm{ng} / \mathrm{ml}$ with the four-step procedure and $1 \cdot 0-2 \cdot 0 \mathrm{ng} / \mathrm{ml}$ with the three-step procedure.

\section{SELIFA for TNase detection}

The sELIFA technique was based on the binding of the TNase filtered through nitrocellulose membranes 


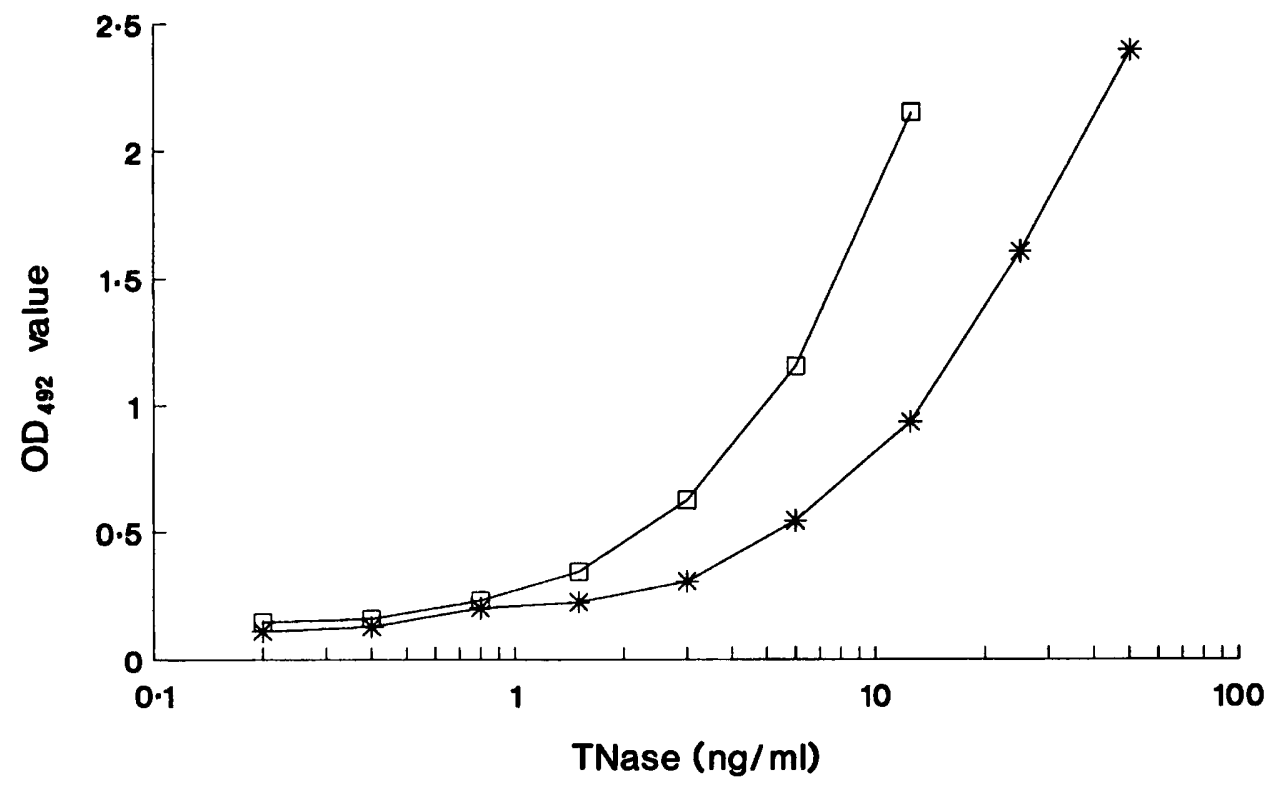

Fig. 2. Two-fold dilutions of commercial TNase tested by the four-step conventional sELISA ( $\boxminus$ ) and by the three-step MAb-peroxidase complex-based sELISA (-*-).

to anti-TNase MAbs pre-spotted on the membranes, followed by detection of the antigen bound to this solid phase with the MAb-peroxidase complex. By filtering the immunoreagents through the solid phase an increase in contact between them was achieved, permitting considerable reduction in reaction time for each immunoreagent.

Nitrocellulose disks in an eight-well strip system

Table I. Bacterial isolates (reference or clinical strains) tested in the TNase enzymatic method and in the sELIFA

\begin{tabular}{|c|c|c|c|}
\hline \multirow{2}{*}{ Species } & \multirow{2}{*}{$\begin{array}{l}\text { Number } \\
\text { tested }\end{array}$} & \multicolumn{2}{|c|}{$\begin{array}{l}\text { Number that gave } \\
\text { positive results in }\end{array}$} \\
\hline & & TNase test* & sELIFA $\dagger$ \\
\hline S. aureus & 28 & 28 & 28 \\
\hline S. epidermidis & 12 & 0 & 0 \\
\hline S. saprophyticus & 1 & 0 & 0 \\
\hline S. hominis & 3 & 0 & 0 \\
\hline S. haemolyticus & 3 & 0 & 0 \\
\hline S. cohnii & 1 & 0 & 0 \\
\hline$S$. intermedius & 6 & 5 & 0 \\
\hline S. hyicus & 5 & 5 & 0 \\
\hline S. capitis & 1 & 0 & 0 \\
\hline S. schleiferi & 6 & 5 & 0 \\
\hline S. sciuri & 1 & 0 & 0 \\
\hline S. auricularis & 1 & 0 & 0 \\
\hline S. simulans & 1 & 0 & 0 \\
\hline S. lugdunensis & 1 & 0 & 0 \\
\hline Streptococcus pyogenes & 1 & 0 & 0 \\
\hline Streptococcus pneumoniae & 2 & 0 & 0 \\
\hline Peptostreptococcus spp. & 1 & 0 & 0 \\
\hline Neisseria meningitidis & 1 & 0 & 0 \\
\hline Escherichia coli & 6 & 0 & 0 \\
\hline Proteus mirabilis & 2 & 0 & 0 \\
\hline Enterobacter cloacae & 2 & 0 & 0 \\
\hline
\end{tabular}

* Positive test defined by a pink zone with diameter $>1 \mathrm{~cm}$ after incubation for $24 \mathrm{~h}^{2}$

$\dagger$ Positive test defined by visual detection of an immunostained spot on the nitrocellulose membrane disks.
A

B

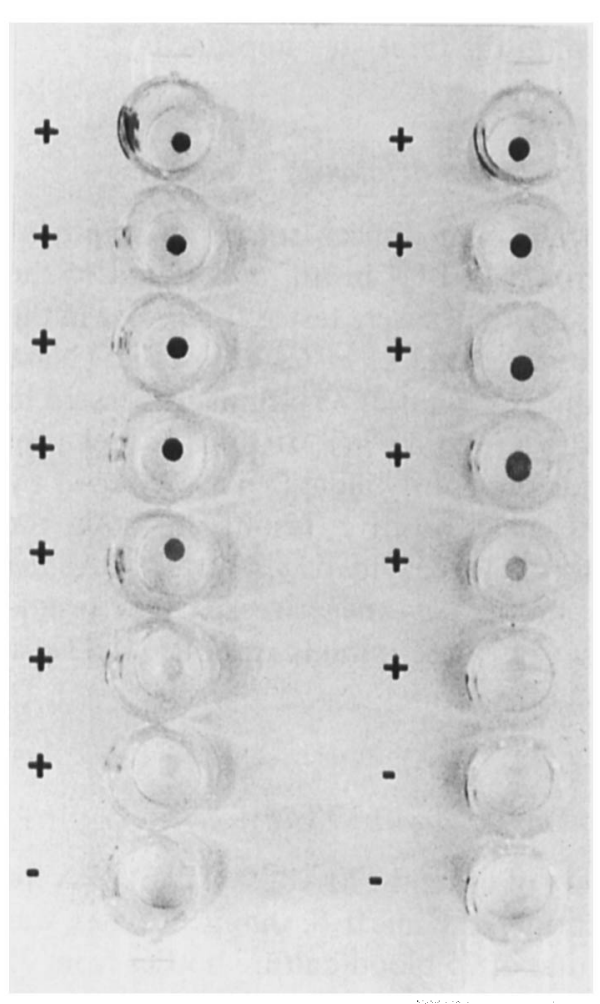

TNase

(ng/ml)

2000

500

125

$31 \cdot 3$

$7 \cdot 8$

$2 \cdot 0$

0.5

0

Fig. 3. Four-fold dilutions of commercial TNase $(400 \mu \mathrm{l})$ tested in sELIFA : A, by a four-step procedure; $\mathbf{B}$, by a three-step complexbased procedure. Positive $(+)$ or negative $(-)$ test result is shown to the left of each well. The control $(0)$ is a test without TNase.

were spotted with the anti-TNase MAb 7F11 and blocked. TNase, wash solutions, and purified MAbperoxidase complex were filtered through the membrane disks at a flow rate of $3 \mathrm{ml} / \mathrm{min}$. The test was performed in $c .10 \mathrm{~min}$ when prepared disks (prespotted and blocked) were available. Fig. 3 shows a lower TNase detection limit of $2 \cdot 0 \mathrm{ng} / \mathrm{ml}$ when the 
Table II. Identification of $S$. aureus directly from blood cultures by the TNase enzymatic test, the TNase sELISA, and the TNase sELIFA

\begin{tabular}{|c|c|c|c|c|}
\hline \multirow{2}{*}{ Blood culture isolate } & \multirow{2}{*}{$\begin{array}{l}\text { Number } \\
\text { tested }\end{array}$} & \multicolumn{3}{|c|}{$\begin{array}{l}\text { Number }(\%) \text { that gave a } \\
\text { positive result in }\end{array}$} \\
\hline & & TNase test* & sELISA $\dagger$ & sELIFA* \\
\hline S. aureus & 40 & $30(75)$ & $37(92)$ & $35(87)$ \\
\hline S. epidermidis & 14 & 0 & 0 & 0 \\
\hline S. haemolyticus & 2 & 0 & 0 & 0 \\
\hline S. schleiferi & 1 & 1 & 0 & 0 \\
\hline$S$. hominis & 2 & 0 & 0 & 0 \\
\hline Str. pyogenes & 1 & 0 & 0 & 0 \\
\hline Str. pneumoniae & 3 & 0 & 0 & 0 \\
\hline Peptostreptococcus spp. & 1 & 0 & 0 & 0 \\
\hline N. meningitidis & 1 & 0 & 0 & 0 \\
\hline E. coli & 6 & 0 & 0 & 0 \\
\hline P. mirabilis & 2 & 0 & 0 & 0 \\
\hline Ent. cloacae & 2 & 0 & 0 & 0 \\
\hline No bacteria & 5 & 0 & 0 & 0 \\
\hline
\end{tabular}

purified MAb-based complexes were used. The lower detection limit was $0.5 \mathrm{ng} / \mathrm{ml}$ when the four-step procedure was performed. The sensitivity was increased to $1.0-0.5 \mathrm{ng} / \mathrm{ml}$ if $2 \mathrm{ml}$ of TNase was filtered instead of $0.4 \mathrm{ml}$ in the three-step approach.

\section{TNases ELIFA for identification of $S$. aureus}

Reference strains and clinical isolates of staphylococci were cultured in BHI broth, and $400 \mu \mathrm{l}$ of the heated culture supernates were tested for TNase in the three-step procedure, and $25 \mu \mathrm{l}$ tested by the TNase enzymatic method. A total of 85 strains was tested in the sELIFA, with a test time of $c .10 \mathrm{~min}$ for each run. All of the strains previously identified as $S$. aureus by other methods gave positive results in both the sELIFA and the TNase enzymatic test (table I). All the non-S. aureus strains gave negative sELIFA results although some of these strains produced TNase activity.

\section{Testing of blood cultures with sELIFA}

The possibility of using the MAb-based sELIFA for rapid identification of clinical $S$. aureus isolates was examined. A total of 75 blood-culture bottles from 75 different patients was tested after signalling of bacterial growth, and five bottles without growth were tested. The positive cultures yielded $S$. aureus (40), non- $S$. aureus staphylococci (19) or other bacteria (16) as determined by standard laboratory tests (table II). The sELIFA permitted identification of the isolate in $87 \%$ of the $S$. aureus-positive cultures within $15 \mathrm{~min}$ after pre-treatment of the samples (heating, centrifugation and filtration). The three-step sELISA and the TNase enzymatic test required 2 and $24 \mathrm{~h}$, respectively, for recording the final results (table II). All cultures from which $S$. aureus was grown and the TNase test result was positive gave positive results in both the sELISA and SELIFA, but the sensitivity of the immunological tests was better than that of the TNase test. One culture with a non-S. aureus strain (S. schleiferi), which gave a positive result in the TNase test, gave negative results in the sELISA and sELIFA (table II). Some cultures from which a few $S$. aureus colonies were grown gave negative results in all three tests. We have found that with different $S$. aureus isolates, $10^{5}-10^{6} \mathrm{cfu} / \mathrm{ml}$ of blood culture are required for detectable levels of the TNase in the antibody-based tests. By adding purified TNase to blood culture media with or without whole blood, incubating for several days, and testing by the four-step sELISA, whole blood components were shown to have both an immediate and a time-dependent negative effect on the sELISA signals.

\section{Discussion}

TNase activity is a characteristic feature of S. aureus, although it is not specific to $S$. aureus. ${ }^{5,6}$ However, data previously reported have indicated that the nuc gene encoding the $S$. aureus TNase and the enzyme protein have $S$. aureus-specific sequences. ${ }^{8,9}$ Thus, provisional data have indicated that both amplification of the nuc gene by the polymerase chain reaction and MAb-based detection of the TNase have potential both for the identification of $S$. aureus isolates and for the rapid confirmation of $S$. aureus infection by direct testing of clinical specimens. ${ }^{9,15}$

The MAb-based four-step sELISA, previously used to detect TNase, ${ }^{9}$ has an operation time of $c .4 \mathrm{~h}$. In the present study we aimed to reduce the operation time by (a) preparation of a four-component MAbbiotin-streptavidin-peroxidase complex for use in a three-step multilayer sELISA, (b) applying the sELIFA which can reduce operation time by the 
increased rate of complexing between the immunoreagents ${ }^{11}$ and (c) a combination of the two approaches.

The high affinity of avidin for biotin ${ }^{10}$ explains our findings that a four-component complex was formed and remained stable after purification by gel filtration. Optimal conditions for complex formation required a ratio of $1: 2$ of the biotinylated MAbs and peroxidasestreptavidin conjugate. Improved complex formation was observed when incubation was started at $4^{\circ} \mathrm{C}$ and then changed to $20^{\circ} \mathrm{C}$; there is no obvious explanation for this. Free MAbs were separated from the fourcomponent complex by gel filtration (fig. 1), and the signal-to-noise ratio was increased when these purified complexes were used, compared with the use of unpurified complexes. This favours the use of the purified four-component complex. In the complexbased sELISA, the lower detection limit was somewhat higher, but the assay time was reduced when compared to the conventional multistep sELISA (fig. 2).

These results have confirmed the findings of IJsselmuiden et $a l .{ }^{11}$ and Shields et $a l .{ }^{16}$ that ELIFA markedly reduced the assay time without affecting the sensitivity considerably, when compared with other multilayer enzyme-linked immunoassays, e.g., sELISA. Thus, the $S$. aureus TNase was detected with an assay time of $10 \mathrm{~min}$ when nitrocellulose membrane disks pre-coated with the grabber MAb and with the remaining binding sites blocked were used. During optimisation of the SELIFA we did not add the chosen blocking reagent (dried milk $1 \%$ ) to immunoreagents, to avoid clogging of the membranes or viscosityinduced hindrance of the filtration flow. ${ }^{17} \mathrm{~A}$ high concentration of Tween $20(>0.05 \%)$ was also omitted to avoid detachment of reagents bound to the solid phase, ${ }^{11,18}$ and adequate signal-to-background discrimination was achieved by using PBS with Tween 20 $0.05 \%$ (fig. 3). The lower detection limit for both the

\section{References}

1. Rappaport T, Sawyer KP, Nachamkin I. Evaluation of several commercial biochemical and immunologic methods for rapid identification of gram-positive cocci directly from blood cultures. J Clin Microbiol 1988; 26: 1335-1338.

2. Berg K, Maeland JA. Same-day confirmation of Staphylococcus aureus bacteraemia by a thermonuclease test. APMIS 1986 ; 94: 291-292.

3. Lachica RVF, Genigeorgis C, Hoeprich PD. Metachromic agar-diffusion methods for detecting staphylococcal nuclease activity. Appl Microbiol 1971; 21 : 585-587.

4. Madison BM, Baselski VS. Rapid identification of Staphylococcus aureus in blood cultures by thermonuclease testing. J Clin Microbiol 1983; 18: 722-724.

5. Gudding R. Differentiation of staphylococci on the basis of nuclease properties. J Clin Microbiol 1983; 18: 1098-1101.

6. Park CE, de Melo Serrano A, Landgraf $M$ et al. A survey of microorganisms for thermonuclease production. Can $J$ Microbiol 1980; 26: 532-535.

7. Shortle D. A genetic system for analysis of staphylococcal nuclease. Gene 1983; 22: 181-189.

8. Liebl W, Rosenstein R, Götz F et al. Use of a staphylococcal nuclease gene as DNA probe for Staphylococcus aureus. FEMS Microbiol Lett 1987; 44: 179-184. complex-based three-step and conventional four-step sELIFAs was $2 \mathrm{ng} / \mathrm{ml}$, if the filtration volume was $0.4 \mathrm{ml}$, but was lowered to $0.5 \mathrm{ng} / \mathrm{ml}$ if filtered volumes were increased to $2 \mathrm{ml}$. It is likely that the sensitivity may be further increased by reducing the flow rate.

All 28 S. aureus strains were identified correctly by the sELIFA when culture supernates of these bacteria were tested. However, the most important application of the sELIFA may be the direct identification of $S$. aureus in blood cultures, since a prompt and reliable detection of $S$. aureus is essential in bacteraemia, which may be life-threatening. In the present study, the sensitivities of the TNase enzyme test, sELISA and sELIFA were $75 \%, 92 \%$, and $87 \%$, respectively, for the direct detection of $S$. aureus in blood cultures. When evaluated for rapid identification of $S$. aureus directly from blood cultures, the sensitivity of six different agglutination reagents which are commercially available ranged from 38.6 to $77 \cdot 3 \% .^{1}$ The sELIFA has the advantage of rapid identification of $S$. aureus after heating and centrifugation of samples of the blood cultures, the assay time is similar to that of agglutination tests, and the clinician can be informed of the results within minutes of the initiation of testing. Blood cultures from which $S$. aureus was isolated, but which gave negative results in our tests, contained comparatively few bacteria. Preliminary experiments have also indicated that components of whole blood reduce the signals for TNase both in the enzymatic test and in the antibody-based tests, and modifications of the methods to eliminate these inhibiting factors will, therefore, be important in increasing the sensitivity of the test. In addition, the tests should have potential for the direct detection of $S$. aureus in other clinical specimens, such as material from abscesses or various body fluids, notably the sELIFA because of its short assay time. This application of the test has not yet been investigated.
9. Brakstad OG, Maeland JA. Generation and characterization of monoclonal antibodies against Staphylococcus aureus thermonuclease. APMIS 1989; 97: 166-174.

10. Green NM. Avidin 1 . The use of $\left[{ }^{14} \mathrm{C}\right]$ biotin for kinetic studies and assay. Biochem $J$ 1963; 89: 585-591.

11. IJsselmuiden OE, Herbrink P, Meddens MJM et al. Optimizing the solid-phase immunofiltration assay. A rapid alternative to immunoassays. J Immunol Methods 1989; 119: 35-43.

12. Reik LM, Maines SL, Ryan DE et al. A simple nonchromatographic purification procedure for monoclonal antibodies. Isolation of monoclonal antibodies against cytochrome P450 isoenzymes. J Immunol Methods 1987; 100: 123-130.

13. Stähli C, Miggiani V, Stocker J et al. Distinction of epitopes by monoclonal antibodies. Methods Enzymol 1983; 92 : 242-253.

14. Bradford MM. A rapid and sensitive method for the quantitation of microgram quantities of protein utilizing principles of protein-dye binding. Anal Biochem 1976; 72 : 248-254.

15. Brakstad OG, Aasbakk K, Maeland JA. Detection of Staphylococcus aureus by polymerase chain reaction amplification of the nuc gene. J Clin Microbiol 1992; 30: 1654-1660.

16. Shields MJ, Siegel JN, Clark CR et al. An appraisal of polystyrene- (ELISA) and nitrocellulose-based (ELIFA) 
enzyme immunoassay systems using monoclonal antibodies reactive toward antigenically distinct forms of human C-reactive protein. J Immunol Methods $1991 ; 141$ : 253-261.

17. IJsselmuiden OE, Meinardi MMHM, Van der Sluis JJ et al. Enzyme-linked immunofiltration assay for rapid sero- diagnosis of syphilis. Eur $J$ Clin Microbiol 1987; 6: 281-285.

18. Hoffman WL, Jump AA. Tween 20 removes antibodies and other proteins from nitrocellulose. $J$ Immunol Methods 1986; 94: 191-196. 